Research Article

\title{
Research on Hysteretic Models for Prestressed and Non-Prestressed Steel Reinforced Concrete Frames
}

\author{
Huihui Luo $\mathbb{D}^{1}$ and Kun Wang $\mathbb{D}^{2,3}$ \\ ${ }^{1}$ College of Guangling, Yangzhou University, Yangzhou 225127, China \\ ${ }^{2}$ College of Civil Science and Engineering, Yangzhou University, Yangzhou 225127, China \\ ${ }^{3}$ Jiangsu Hanjian Group Company Limited, 225000, China
}

Correspondence should be addressed to Huihui Luo; 060137@yzu.edu.cn

Received 3 July 2021; Accepted 24 September 2021; Published 12 October 2021

Academic Editor: Zhiyong Chen

Copyright ( $(2021$ Huihui Luo and Kun Wang. This is an open access article distributed under the Creative Commons Attribution License, which permits unrestricted use, distribution, and reproduction in any medium, provided the original work is properly cited.

\begin{abstract}
The beam-column fibre model is used to simulate the entire hysteretic process of the prestressed and non-prestressed steel reinforced concrete frame, and the results are compared with the test results. Based on the analysis of a large number of parameters, the hysteretic curve characteristics of this kind of composite frame are discussed, and the load-displacement hysteretic models of single-storey and single-span composite frame are established. The models can comprehensively consider the influence of axial compression ratio and column slenderness ratio and can predict the hysteretic behaviour of this kind of composite frame under horizontal loads. The load-displacement hysteretic models are consistent with the numerical simulation results. Relevant research can provide reference for simplifying the elastic-plastic dynamic analysis of structures.
\end{abstract}

\section{Introduction}

Prestressed steel reinforced concrete structures have the advantages of high bearing capacity and good seismic performance, which have been widely used in practical engineering, especially in the super-span and out-jacketing frame structure [1-4]. However, due to the uneven distribution of lateral stiffness and bearing capacity along the height of the out-jacketing building, it is necessary to have a comprehensive grasp of its overall seismic performance under rare earthquakes $[5,6]$. As mathematical models of the relationship between restoring force and deformation obtained after abstraction and simplification, the hysteretic models can better reflect the seismic performance of structures or components and have been extensively studied.

At present, at the level of components, Xue et al. [7] established the $M-\varphi$ hysteretic models of prestressed steel reinforced concrete beams. Zheng et al. [8] proposed the $M$ $\varphi$ hysteretic models of angle-steel concrete columns based on the experimental results and numerical simulations. At the level of frame structure, Wang et al. [9] built a practical hysteretic model for concrete filled steel tubular frame, which can effectively predict the mechanical behaviour of the frame. Hu et al. [10] presented the hysteretic models of steel frames infilled with the reinforced concrete deep beam with the skeleton curves as a three-fold line based on the test results. Wang et al. [11] developed a simplified hysteretic model based on the analysis of experimental results, which can better describe the hysteretic performance of the frame under repeated loads. It can be seen that almost of the above studies involve the hysteretic characteristics of the combined frame proposed in this paper, and the idea and method of establishing the hysteretic model provide an important reference basis for the study in this paper.

For this reason, a numerical model of a single-storey and single-span frame was proposed for prestressed and nonprestressed steel reinforced concrete frames, which was compared with the tested results. Through the analysis of a large number of parameters by using the numerical model, the characteristics of hysteretic curves of this type of the composite frame were analysed, and the horizontal loaddisplacement hysteresis models of this type of single-storey 
and single-span composite frame were obtained by statistical regression and compared with the results of numerical calculation, which provided a reasonable basis for the elastoplastic dynamic analysis of simplified structure.

\section{Numerical Models}

2.1. The Establishment of the Models. In this paper, a numerical analysis model of a single-storey and single-span frame was established for both prestressed and non-prestressed steel reinforced concrete frame structures based on the seismic analysis platform OpenSees [12]. The prestressed tendons in the frame beams were arranged in the form of three-segment parabola and each cross section had a certain variation, so the lumped plastic hinge fibre element named Beam with Hinges Element was used to simulate the beams. Since the cross section was the same in the axial direction for frame columns, the distributed plastic hinges beam-column fibre element named Nonlinear Beam Column Element was adopted in this paper. Reference [13] describes the two-stage principle of prestressing: in the first stage, the concentrate forces and moments at two beam ends and the equivalent load on beam between joints are conceived as external loads when effective prestressing stress is built though tensioning the tendons; in the second stage, the redundant strength exceeding the effective prestressing stress in tendons is used to resist the additional external loads, and thus the tendons with redundant strength could be thought as materials. The node arrangement and section division of the prestressed steel concrete frame model as well as loading patterns are presented in Figure 1. In the figure, the frame beam is divided into 6 elements according to the prestressed equivalent load, the vertical load distribution, and the midspan point. The nodes were, respectively, set at the beam end, the middle span, the point of inflection for prestressed reinforcement, and the vertical concentrated load points. Each frame column was divided into one element, and the bottom of the frame column was rigidly connected to the foundation. The horizontal cyclic load $P$ was imposed on node 3 at the left end of the frame beam, the vertical concentrated forces $N_{1}$ were applied on nodes 3 and 4 , and concentrated loads $N_{2}$ were exerted on nodes 5 and 6 on the beam. When the crosssectional area of the prestressed tendons was zero, the model can be transformed into a non-prestressed steel reinforced concrete frame. For the beams and columns, the crosssectional concrete was divided into two portions due to the confinement effect of stirrups, which were concrete cover and concrete confined by stirrups. In addition, the connection of beams and columns in the numerical model is rigidly connected.

\section{Material Constitutive Relationship}

The concrete adopted the model Concrete 01 provided in OpenSees (see Figure 2). In the figure, $f_{\mathrm{c}}$ is the compressive strength of concrete cylinder, $K$ is the coefficient of strength increase due to constraint consideration, $\varepsilon_{0}$ is the peak strain, $\varepsilon_{p}$ is the compressive strain after unloading, $\varepsilon_{r}$ is the compressive strain at the unloading point, and $\varepsilon_{u}$ is the ultimate compressive strain. No influence of concrete under tension was considered in this model, and the stress-strain relationship of uniaxial compression was from the Kent-Park model modified by Scott [14-16]. The hysteretic rule of Concrete01 model was based on the hysteretic model provided by Karsan and Jirsa. To simplify the analysis, the confinement effect of the steel embedded in the beam and column was not considered in the modelling. Therefore, beam and column sections were only divided into concrete core and concrete cover without stirrup confinement, and confined and unconfined concrete models were adopted, respectively.

The steel adopted the steel02 model in OpenSees, which was a bilinear kinematic hardening model considering the Bauschinger effect. The prestressed reinforcement adopted the Elastic Perfectly Plastic Material model in OpenSees. According to the two-stage principle of prestressing, the residual strength of the prestressed tendons took the stressstrain relationship displayed in Figure 3, and unloading and reloading were carried out along a straight line, after the effective prestress was deducted from the second-stage prestressed tendons of the external load. In the figure, $f_{\mathrm{p} 0.2}$ is the conditional yield strength, $\sigma_{\mathrm{pe}}$ is the effective prestress of prestressed reinforcement, and $E_{\mathrm{p}}$ is the initial stiffness.

3.1. Test Verification. Fu et al. [3] fabricated one specimen of ordinary steel reinforced concrete frame and one of prestressed steel reinforced concrete frame according to the scale of $1 / 3$ on the basis of practical engineering. The two specimens were named SRCF and PSRCF, respectively, and the reinforcements are described in Figures 4(a) and 4(b). Figure $4(\mathrm{c})$ gives the loading patterns, where two vertical concentrate loads of $40 \mathrm{kN}$ were imposed on the beam, and a horizontal cyclic load $\pm P$ was applied at left end of the beam. The two frame specimens were designed according to "strong column and weak beam" and "strong joints and weak members." The column cross section dimensions of the two frame specimens were the same, both were $230 \mathrm{~mm} \times 230 \mathrm{~mm}$, and welded H-shaped steel $\mathrm{HN} 130 \times 110 \times 4 \times 10$ was arranged in the columns. The cross section size of the frame beam of the specimen SRCF was $150 \mathrm{~mm} \times 230 \mathrm{~mm}$, and the size of the $H$-shaped steel placed in the centre was $\mathrm{HN} 130 \times 50 \times 4 \times 14$. The frame beam section size of the prestressed specimen PSRCF was $150 \mathrm{~mm} \times 230 \mathrm{~mm}$, and the size of the embedded welded $\mathrm{H}$-shaped steel was $\mathrm{HN} 130 \times 50 \times 4 \times 8$. In order to facilitate the arrangement of the prestressed tendons, the section steel web was offset on one side, and a steel strand with grade of 1860 and a diameter of $12.7 \mathrm{~mm}$ was taken as the prestressed reinforcement. By measurement, the tension control stress was $1395 \mathrm{MPa}$ and the actual effective prestress was $970 \mathrm{MPa}$.

The strength grade of stirrups of beams and columns was HPB235, while the strength grade of longitudinal reinforcements was HRB400 and the structural steels were welded with Q235 steel plates. The specimens were poured on-site and made of commercial fine stone concrete. The measured compressive strength $f_{\text {cu }}$ of concrete cube was 


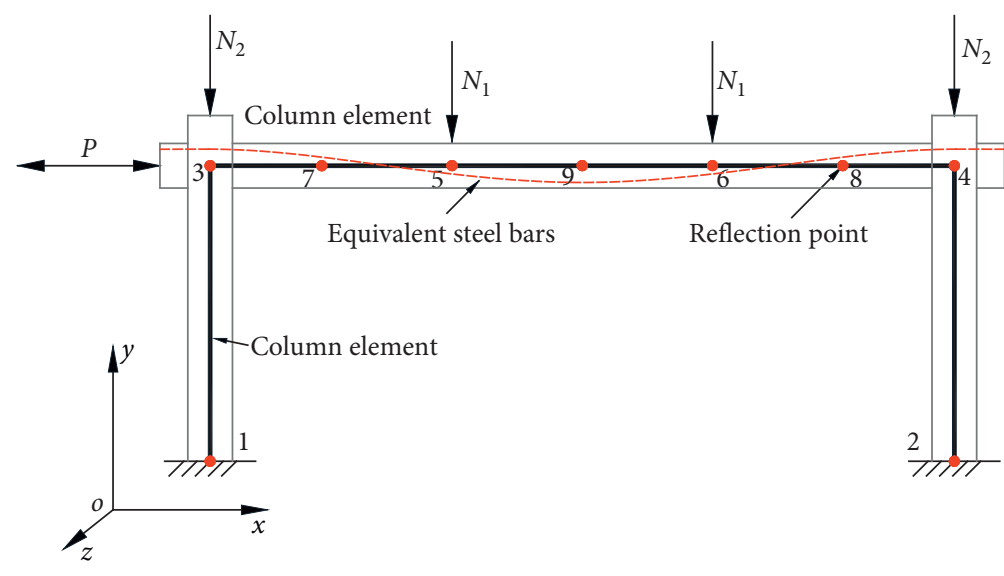

(a)

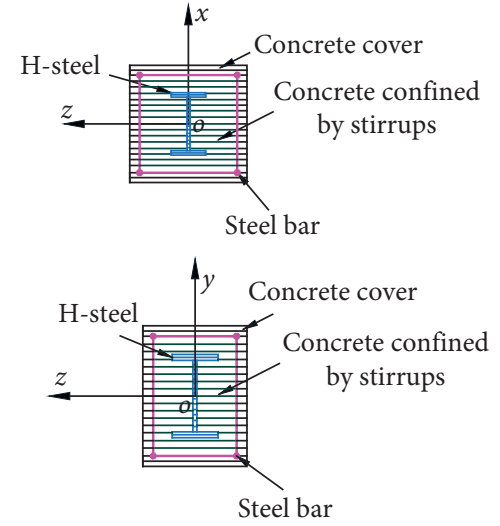

(b)

FIgure 1: Node layout and element section division. (a) Node distribution. (b) Division of cross section.



Figure 2: Constitutive model of concrete.

$41 \mathrm{MPa}$, and the modulus of elasticity $E_{\mathrm{c}}$ was $3.17 \times 104 \mathrm{MPa}$. The tested yield strength $f_{\mathrm{y}}$ of $\$ 25, \$ 14, \$ 12$, and $\Phi 6$ steel bars was $412 \mathrm{MPa}, 398 \mathrm{MPa}, 487 \mathrm{MPa}$, and $305 \mathrm{MPa}$, respectively. In the test, the horizontal load and displacement were measured. The hysteretic properties of two steel concrete frame specimens under low horizontal cyclic loading were studied, and the hysteretic curves, skeleton curves, and energy dissipation capacities of the specimens were investigated.

The comparison between the numerical calculation and the experimental hysteresis curves was described (see Figure 5). It can be seen that the calculated curves and the experimental curves generally agree with each other in bearing capacity, stiffness degradation, and hysteresis loop shape, reflecting the correctness of the model built.

\section{Hysteresis Curve Characteristics}

4.1. Impact Parameters. In order to further study the hysteretic characteristics of prestressed and non-prestressed steel reinforced concrete frames, parameter analysis was conducted to observe the main influence factors on the seismic performance in this paper, which include the column slenderness ratio $(\beta)$, axial compression ratio $\left(n_{0}\right)$, compressive strength of concrete cube $\left(f_{\text {cu }}\right)$, sectional resistance moment of shaped steel in beams and columns ( $W_{\text {ss- }}$ $c$ and $\left.W_{\text {ss-b }}\right)$, ratio of longitudinal reinforcement in beams and columns ( $\rho_{\mathrm{s}-\mathrm{b}}$ and $\left.\rho_{\mathrm{s}-\mathrm{c}}\right)$, yield strength of shaped steel in beams and columns $\left(f_{\text {ss-b }}\right.$ and $\left.f_{\text {ss-c }}\right)$, yield strength of longitudinal bars in beams and columns $\left(f_{\mathrm{y}-\mathrm{b}}\right.$ and $\left.f_{\mathrm{y}-\mathrm{c}}\right)$, and prestressing degree $(\lambda)$.

Neglecting the contribution of steel web, the prestressing degree $(\lambda)$ could be computed as follows:

$$
\gamma=\frac{A_{p} f_{p y} h_{p}}{A_{p} f_{p y} h_{p}+A_{s f-b} f_{s s-b} h_{s s-b}+A_{s-b} f_{y-b} h_{s-b}},
$$

where $A_{p}, A_{s f-b}$, and $A_{s-b}$ represent the cross-sectional areas for tendons, tensile flange of shaped steel, and tensile longitudinal rebars in beam, respectively; $f_{p y}$ is the tensile yielding strength for tendons; and $h_{p}, h_{s s-b}$, and $h_{s-b}$ represent the distances from centroid of tendons, tensile flange of shaped steel, and tensile longitudinal rebars to extreme compressive fibre, respectively.

The hysteretic analysis parameters of prestressed and non-prestressed steel reinforced concrete frames are presented in Table 1.

4.2. Parameter Analysis. The influences of different slenderness ratios, axial compression ratios, cubic concrete strengths, sectional resistance moment of shaped steel in column, longitudinal reinforcement ratios, and prestressed degrees on the horizontal load-displacement hysteretic curves of prestressed steel reinforced concrete frames are described in Figure 6. The corresponding skeleton curves are provided in Figure 7, and Table 2 gives the critical values of the skeleton curves in the positive direction. It could be observed that

(1) The peak load of prestressed frame decreased with the increase of column slenderness ratio, but the 


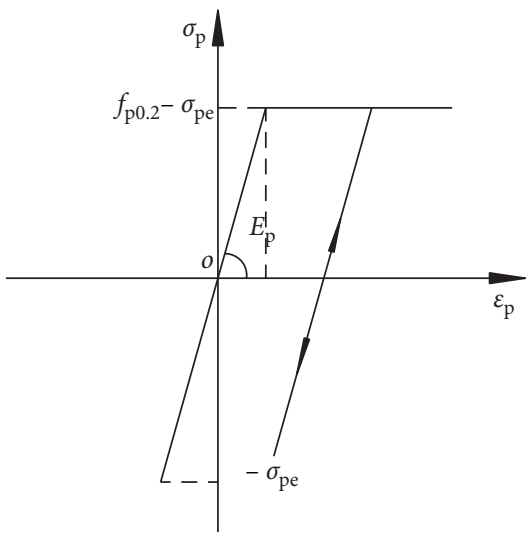

Figure 3: Model of prestressed reinforcement.
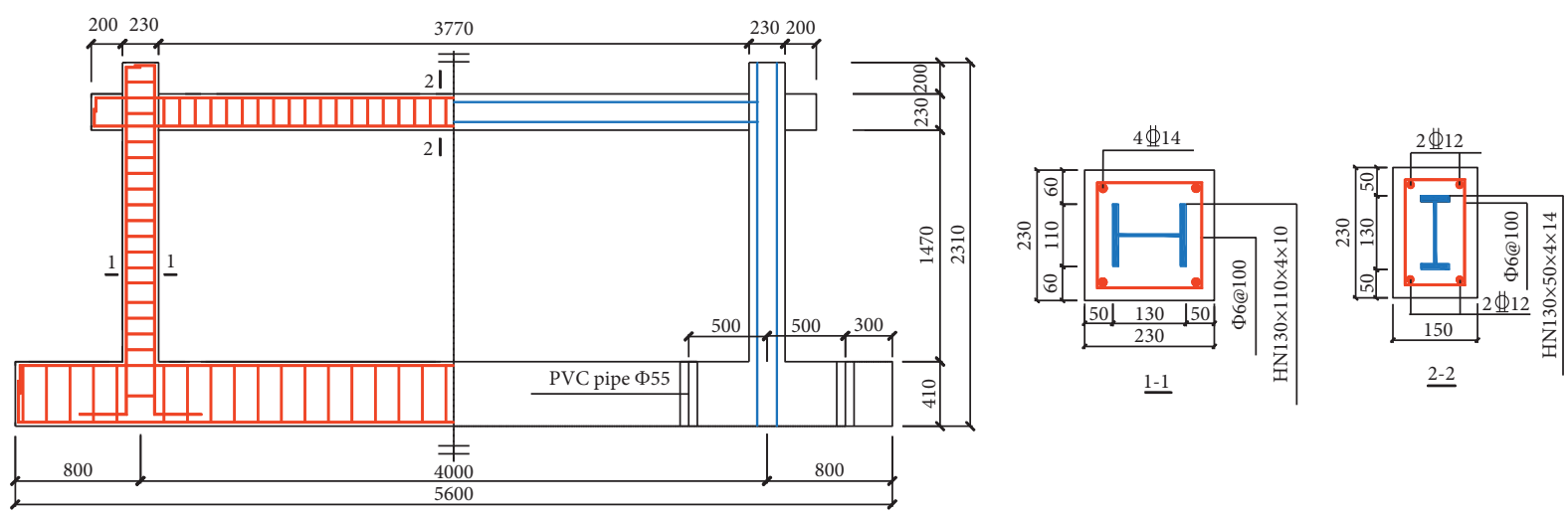

(a)
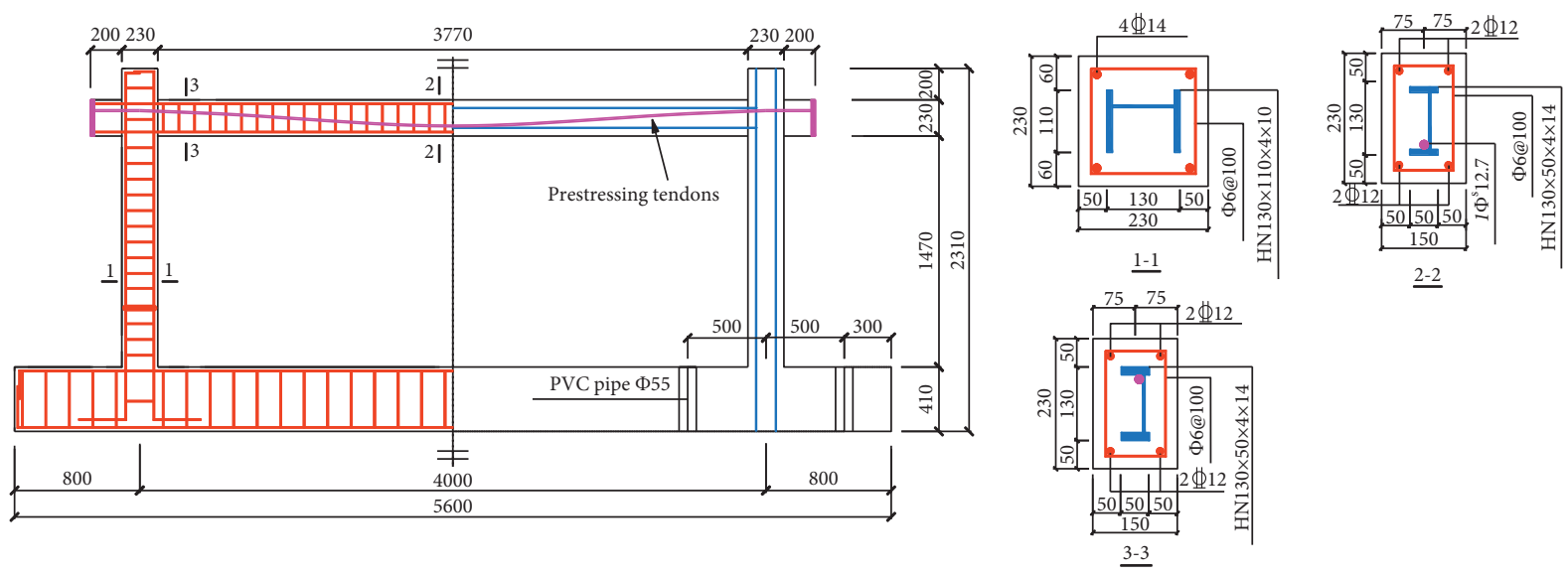

(b)



(c)

Figure 4: Size of frame specimen. (a) Specimen SRCF. (b) Specimen PSRCF. (c) Loading sketch. 


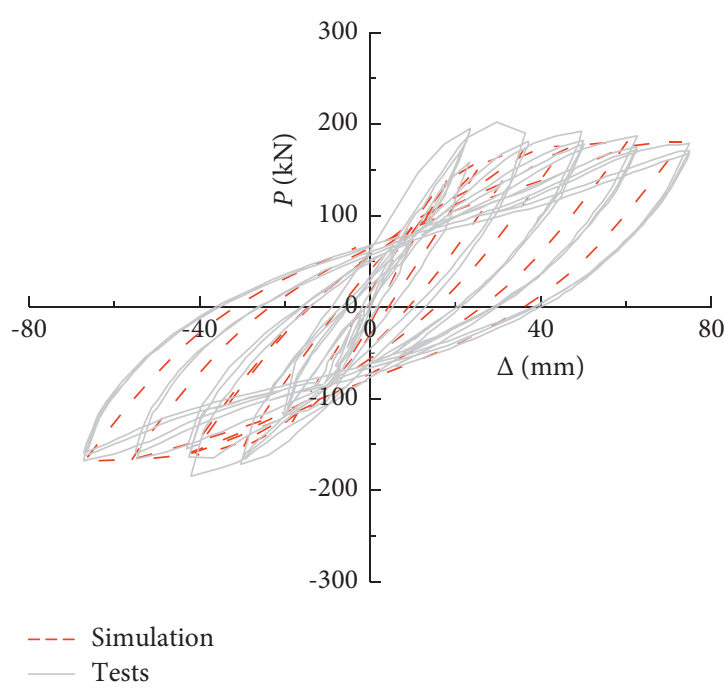

(a)

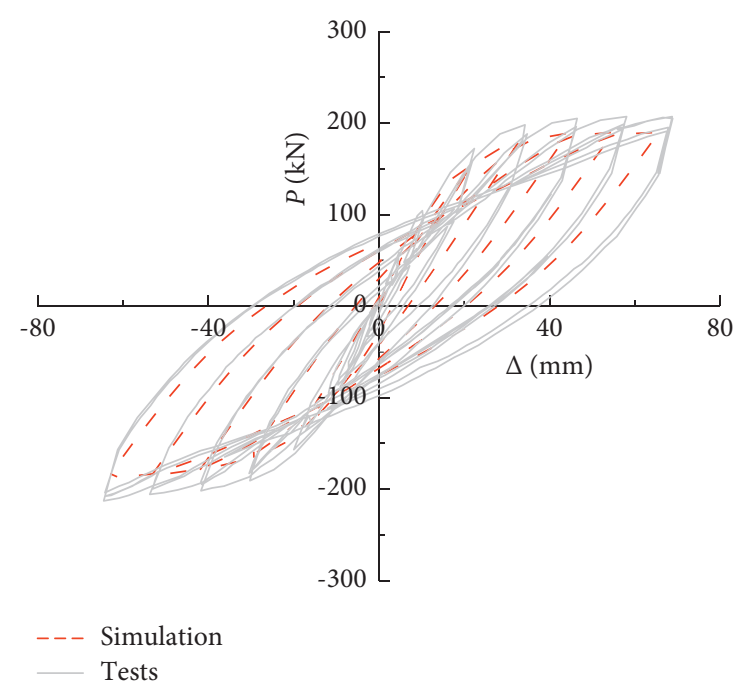

(b)

FIgure 5: Comparison of hysteretic curves for specimens obtained from test and calculation. (a) Specimen SRCF. (b) Specimen PSRCF.

TABLE 1: Analysis parameters.

\begin{tabular}{|c|c|c|c|c|}
\hline \multirow[b]{2}{*}{ Parameter category } & \multicolumn{2}{|r|}{ PSRCF } & \multicolumn{2}{|r|}{ SRCF } \\
\hline & $\begin{array}{l}\text { Parameter } \\
\text { change range }\end{array}$ & Remarks & $\begin{array}{l}\text { Parameter's } \\
\text { range }\end{array}$ & Remarks \\
\hline Column slenderness ratio $\beta$ & $6 ; 8 ; 10 ; 12$ & $\begin{array}{l}\text { Corresponding column height: } \\
1500 \mathrm{~mm} ; 2000 \mathrm{~mm} ; 2500 \mathrm{~mm} \text {; } \\
3000 \mathrm{~mm}\end{array}$ & $6 ; 8 ; 10 ; 12$ & $\begin{array}{l}\text { Corresponding column height: } \\
1500 \mathrm{~mm} ; 2000 \mathrm{~mm} ; 2500 \mathrm{~mm} \text {; } \\
3000 \mathrm{~mm}\end{array}$ \\
\hline Axial compression ratio $n_{0}$ & $0.1 ; 0.2 ; \ldots ; 0.8$ & - & $0.1 ; 0.2 ; \ldots ; 0.8$ & - \\
\hline Concrete strength $f_{\mathrm{cu}}(\mathrm{MPa})$ & $30,40,50$ & - & $30,40,50$ & - \\
\hline $\begin{array}{l}\text { Sectional resistance moment } \\
\text { of shaped steel in beam } W_{\text {ss-b }} \\
\left(\mathrm{mm}^{3}\right)\end{array}$ & $82.126,64.521$ & $\begin{array}{l}\text { Corresponding H-shaped steel: } \\
\mathrm{H} 180 \times 50 \times 4 \times 8 ; \mathrm{H} 150 \times 50 \times 4 \times 8\end{array}$ & $82.126,64.521$ & $\begin{array}{l}\text { Corresponding H-shaped steel: } \\
\mathrm{H} 180 \times 50 \times 4 \times 8 ; \mathrm{H} 150 \times 50 \times 4 \times 8\end{array}$ \\
\hline $\begin{array}{l}\text { Sectional resistance moment } \\
\text { of shaped steel in column } \\
W_{\text {ss-c }}\left(\mathrm{mm}^{3}\right)\end{array}$ & $\begin{array}{l}256.281 \\
206.098\end{array}$ & $\begin{array}{l}\mathrm{H} 180 \times 150 \times 4 \times 10 \\
\mathrm{H} 150 \times 150 \times 4 \times 10\end{array}$ & $\begin{array}{l}256.281 \\
206.098\end{array}$ & $\begin{array}{c}\mathrm{H} 180 \times 150 \times 4 \times 10 \\
\mathrm{H} 150 \times 150 \times 4 \times 10\end{array}$ \\
\hline $\begin{array}{l}\text { Reinforcement ratio of } \\
\text { longitudinal steel bars in } \\
\text { beam } \rho_{\mathrm{s}-\mathrm{b}}\end{array}$ & $\begin{array}{l}0.785 \% \\
1.131 \% \\
1.539 \% \\
\end{array}$ & $4 \nsubseteq 10,4 \nsubseteq 12,4 \nsubseteq 14$ & $\begin{array}{c}0.785 \%, 1.131 \% \\
1.539 \%\end{array}$ & $4 \nsubseteq 10,4 \Phi 12,4 \Phi 14$ \\
\hline $\begin{array}{l}\text { Reinforcement ratio of } \\
\text { longitudinal steel bars in } \\
\text { column } \rho_{\mathrm{s}-\mathrm{c}}\end{array}$ & $\begin{array}{c}0.724 \% \\
0.985 \% \\
1.287 \% \\
\end{array}$ & $4 \nsubseteq 12,4 \nsubseteq 14,4 \nsubseteq 16$ & $\begin{array}{c}0.724 \% \\
0.985 \%, 1.287 \%\end{array}$ & $4 \Phi 12,4 \nsubseteq 14,4 \Phi 16$ \\
\hline $\begin{array}{l}\text { Yield strength for shaped } \\
\text { steels } f_{\text {ss-b }} \text { and } f_{\text {ss-c }}(\mathrm{MPa})\end{array}$ & $235,345,390$ & Q235, Q345, Q390 & $235,345,390$ & Q235, Q345, Q390 \\
\hline $\begin{array}{l}\text { Yield strength of longitudinal } \\
\text { steel bars } f_{\mathrm{y}-\mathrm{b}} \text { and } f_{\mathrm{y}-\mathrm{c}}(\mathrm{MPa})\end{array}$ & $300,335,400$ & HPB300, HRB335, HRB400 & $300,335,400$ & HPB300, HRB335, HRB400 \\
\hline Prestressed degree $\lambda$ & $0.31,0.45,0.54$ & $1 \Phi^{\mathrm{s}} 9.5,1 \Phi^{\mathrm{s}} 12.7,1 \Phi^{\mathrm{s}} 15.2$ & - & - \\
\hline
\end{tabular}

displacement corresponding to the peak load increased; after the skeleton curves reached the peak loads, the descending segment gradually became gentle and the ductility was improved obviously; the hysteretic curves of the frame behaved plump and no pinching occurred.

(2) When the axial compression ratio was relatively small, the hysteretic curves were plump and the hysteretic loops had shuttle shape; as the axial compression ratio increased, the horizontal peak load first increased and then decreased; when the axial compression ratio was greater than 0.5 , the horizontal displacement at peak load was decreased, and the ductility of the frame was obviously reduced. At this time, the hysteresis loops pinched a certain amount.

(3) With the increase of cubic concrete strength, the peak loads of the skeleton curves were enhanced, the displacement corresponding to the peak load had almost no changes, and the stiffnesses of the descending segments were the same. 

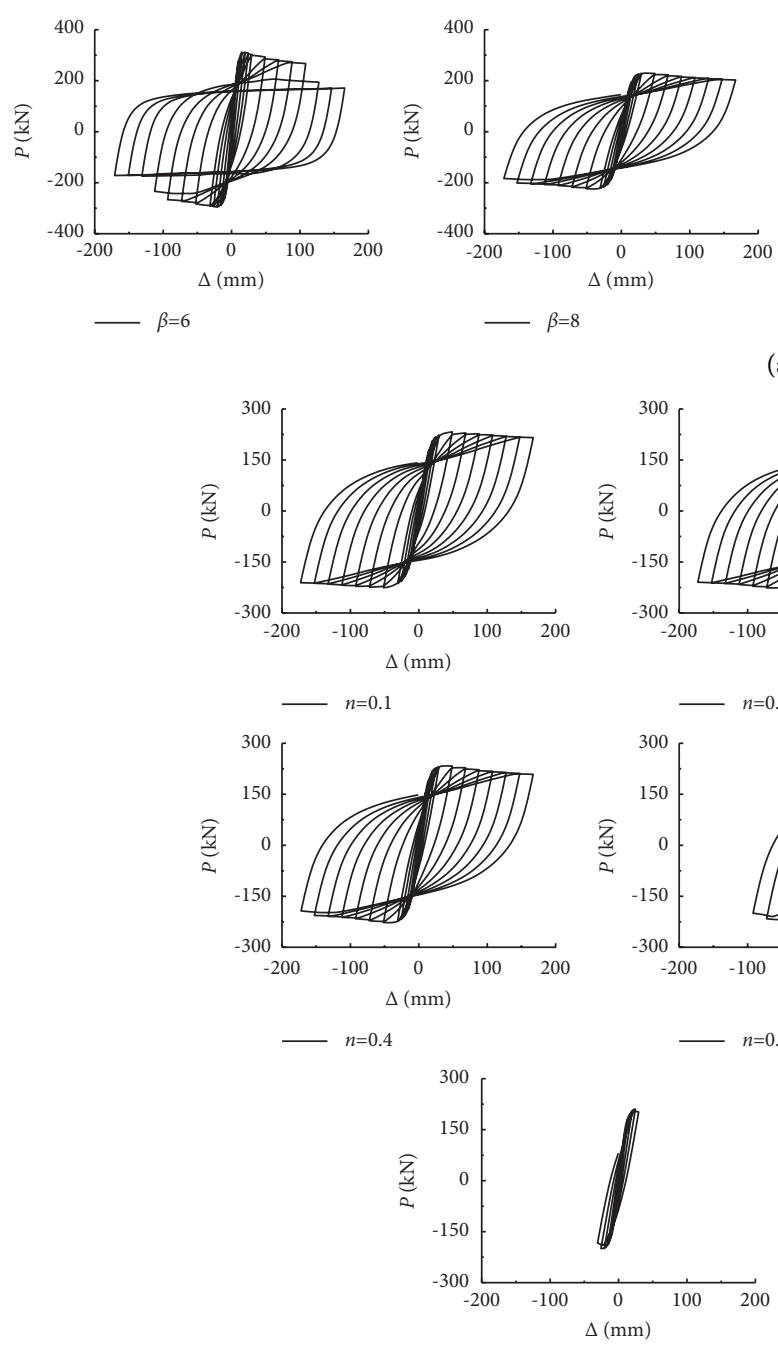

— $n=0.7$
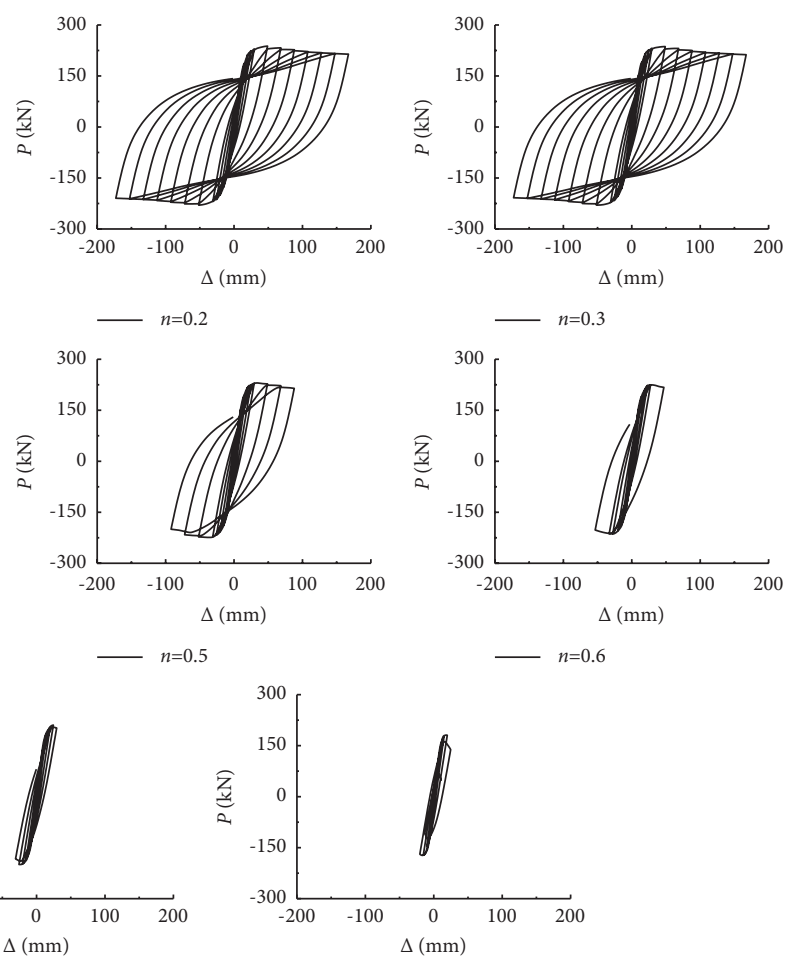

(b)
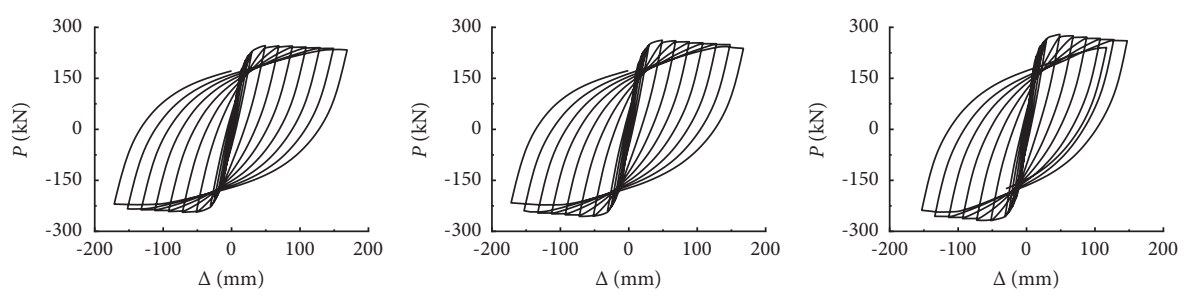

- $f_{c}=30 \mathrm{MPa}$

(c)
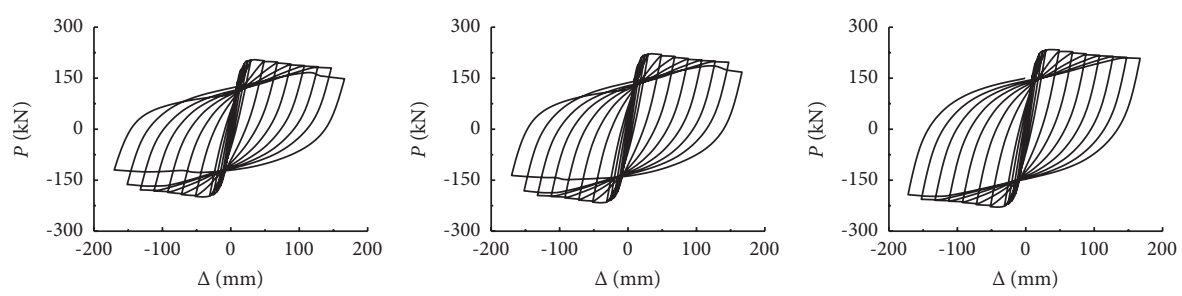

$-W_{\mathrm{ss}-c}=206.098 \mathrm{~mm}^{3}$

$-W_{s s-c}=256.281 \mathrm{~mm}^{3}$

(d)

FIgURE 6: Continued.

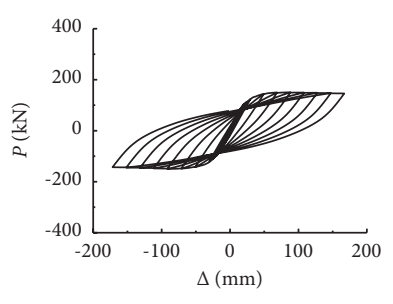

$-\beta=12$ 

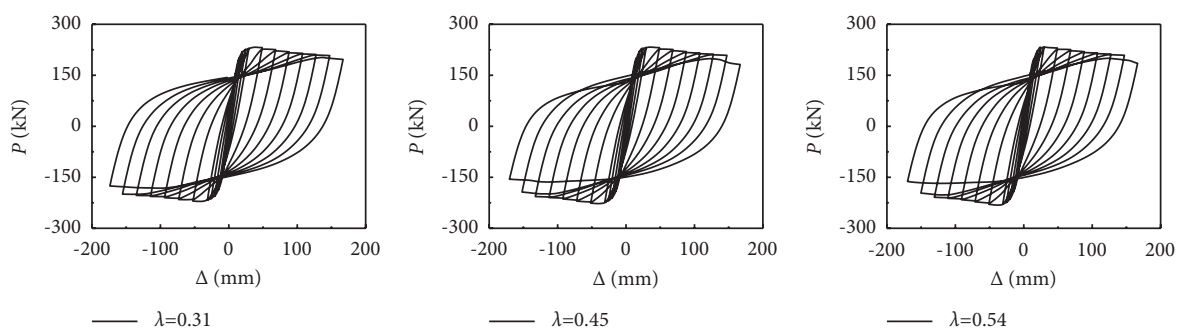

(e)

Figure 6: The influence of different parameters on the hysteresis curves. (a) Column slenderness ratio. (b) Axial compression ratio. (c) Cubic concrete strength. (d) Sectional resistance moment of shaped steel and longitudinal reinforcement ratio in the column. (e) Prestressing degree.



(a)
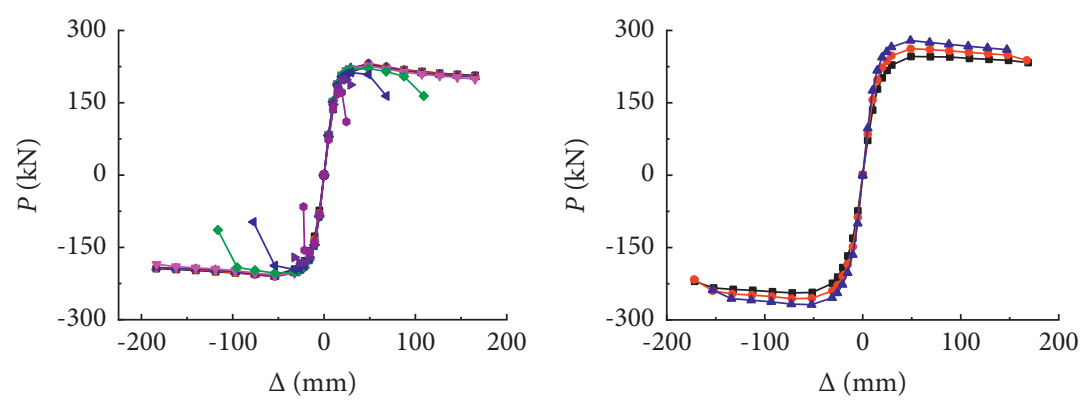

$$
\begin{aligned}
& \longrightarrow n_{0}=0.1 \quad \rightarrow n_{0}=0.2 \\
& \longrightarrow n_{0}=0.3 \quad \rightarrow n_{0}=0.4 \\
& \rightarrow n_{0}=0.5 \quad \longrightarrow n_{0}=0.6 \\
& \rightarrow n_{0}=0.7 \quad \rightarrow n_{0}=0.8
\end{aligned}
$$

(b)

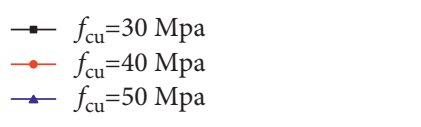

(c)



(d)

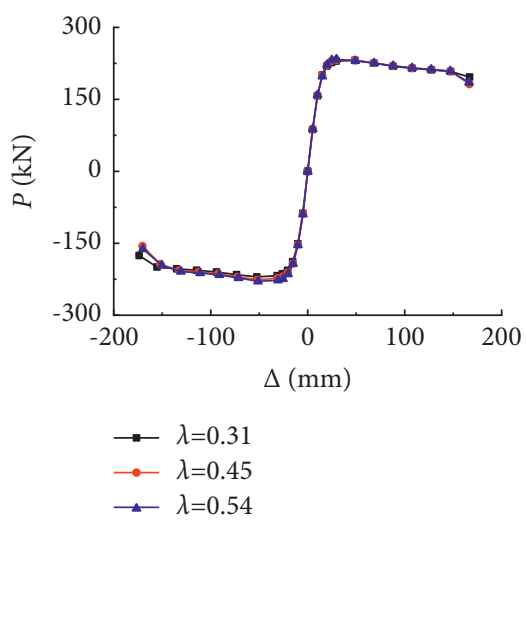

(e)

FIgURE 7: The influence law of different parameters on the skeleton curves. (a) Column slenderness ratio. (b) Axial compression ratio. (c) Cubic concrete strength. (d) Sectional resistance moment of shaped steel and longitudinal reinforcement ratio in the column. (e) Prestressed degree.

(4) With the increase of the sectional resistance moment of shaped steel and longitudinal reinforcement ratio in columns, the hysteretic curves became fuller, and the horizontal peak load increased, while the displacements corresponding to the peak loads as well as the stiffnesses of descending segments kept almost unchanged.
(5) Due to the existence of internal shaped steels, the hysteretic curves with varying prestressed degree showed no apparent distinction. The increase of prestressed degree can only slightly increase the horizontal bearing capacity of the frame; however, it had little influence on the initial stiffness, the 
TABLE 2: Characteristics of skeleton curves under different analytical parameters in positive direction.

\begin{tabular}{|c|c|c|c|c|c|}
\hline Analytical parameters & $K_{\mathrm{y}}(\mathrm{kN} / \mathrm{mm})$ & $\Delta_{y}(\mathrm{~mm})$ & $\Delta_{m}(\mathrm{~mm})$ & $P_{m}(\mathrm{kN})$ & $K_{d}(\mathrm{kN} / \mathrm{mm})$ \\
\hline$\beta=6$ & 27.3 & 10.2 & 19.7 & 312.1 & 0.503 \\
\hline$\beta=8$ & 12.4 & 16.3 & 29.5 & 228.7 & 0.187 \\
\hline$\beta=10$ & 6.5 & 24.7 & 49.2 & 182.8 & 0.110 \\
\hline$\beta=12$ & 3.8 & 34.3 & 88.4 & 150.7 & 0.058 \\
\hline$n_{0}=0.1$ & 9.7 & 20.6 & 48.7 & 226.6 & 0.171 \\
\hline$n_{0}=0.3$ & 11.0 & 18.4 & 48.6 & 230.4 & 0.230 \\
\hline$n_{0}=0.5$ & 12.2 & 16.2 & 48.6 & 221.2 & 0.660 \\
\hline$n_{0}=0.7$ & 12.7 & 14.0 & 24.2 & 197.8 & 2.135 \\
\hline$f_{\mathrm{cu}}=30 \mathrm{MPa}$ & 9.1 & 23.6 & 49.4 & 246.0 & 0.106 \\
\hline$f_{\mathrm{cu}}=40 \mathrm{MPa}$ & 10.6 & 21.5 & 49.0 & 262.1 & 0.203 \\
\hline$f_{\mathrm{cu}}=50 \mathrm{MPa}$ & 12.2 & 20.1 & 48.8 & 279.2 & 0.192 \\
\hline$W_{\mathrm{ss}-\mathrm{c}}=256.281 ; \rho_{\mathrm{s}-\mathrm{s}}=1.287 \%$ & 12.2 & 16.0 & 29.5 & 221.2 & 0.263 \\
\hline$W_{\mathrm{ss}-\mathrm{c}}=268.281 ; \rho_{\mathrm{s}-\mathrm{c}}=0.724 \%$ & 12.6 & 16.3 & 29.5 & 233.3 & 0.182 \\
\hline$W_{\text {ss-c }}=206.098 ; \rho_{\mathrm{s}-\mathrm{c}=}=0.724 \%$ & 11.2 & 16.2 & 29.5 & 204.3 & 0.247 \\
\hline$\lambda=0.31$ & 12.7 & 16.2 & 49.1 & 233.3 & 0.314 \\
\hline$\lambda=0.45$ & 12.6 & 16.2 & 29.5 & 232.1 & 0.270 \\
\hline$\lambda=0.54$ & 12.6 & 16.4 & 29.7 & 233.3 & 0.259 \\
\hline
\end{tabular}

displacement at peak load, and the stiffness of the descending branch of the skeleton curves.

Other factors, such as the sectional resistance moment of shaped steel and longitudinal reinforcement ratio in the beam, the yield strength of the shaped steel, and the longitudinal reinforcement both in beams and columns, had the same effects as the sectional resistance moment of shaped steel in the columns. In addition, the influence of various analysis parameters on the hysteretic and skeleton curves for the nonprestressed steel reinforced concrete frame was analogous to that of the prestressed ones, which were omitted here.

4.3. Characteristics of Hysteresis Curves. As can be seen by calculated hysteretic curves, in the initial stage of loading, the hysteretic curves behaved as a straight line passing through the origin in two directions, and the loading and unloading curves coincided, which means that the composite frame is in the elastic working stage; as the loading displacement increased, the skeleton curves gradually deviated from the straight line, and a certain unloading deformation appeared, and as the unloading displacement increases, the unloading stiffness decreases slightly. When the axial compression ratio did not exceed the value of 0.5 , the calculated hysteretic curves were relatively plump, showing a stable shuttle shape, and no obvious pinch formed.

It can be found from the skeleton curves that the column slenderness ratio and axial compression ratio had significant influence on the initial stiffness, displacement at peak load, and the stiffness of the descending segment, while the other factors had almost no impact on the shape of the skeleton curves.

\section{Horizontal Load-Displacement Hysteretic Models}

Based on the analysis of a large number of parameters, the horizontal load-displacement hysteretic models of singlestorey and single-span prestressed and non-prestressed steel reinforced concrete frames were regressed in this paper, which were suitable for such frame structure.

5.1. Skeleton Curves. The skeleton curves of the hysteretic model adopt a degenerate trilinear model shown in Figure 8, where five parameters are needed to be determined, namely, the yield stiffness $K_{y}$, the horizontal yield load $P_{y}$, the horizontal peak load $P_{m}$, the peak point displacement $\Delta_{m}$, and the descending branch stiffness $K_{d}$. It is demonstrated from the foregoing analysis that prestressed degree had a certain effect on the peak load of the skeleton curves. Due to the fact that the peak load was mainly related to the flexural capacity of beam and the influence of prestressing tendons had been considered to compute the flexural capacity of beam, to simplify the analysis, the axial compression ratio and slenderness ratio are taken as the major factors to establish the skeleton curve model, and the influence of prestressing degree was not considered repeatedly.

(1) According to the initial bending stiffness of the beam and column section, the size of the specimen, and the load distribution patterns, elastic theory and numerical regression can be used to establish the expression of the initial frame stiffness $K_{\mathrm{y}}$ as follows:

$$
K_{\mathrm{y}}=\left(1.412+0.39 n_{0}-0.043 \beta-0.69 n^{2}+0.066 n_{0} \beta\right) K_{\mathrm{e}} \text {. }
$$

Among them,

$$
\begin{aligned}
K_{e} & =\frac{3 E I_{c}}{L_{2}^{3}} \cdot \frac{12+36 k}{3(4+3 k)}, \\
k & =\frac{E I_{b} / 0.5 L_{1}}{E I_{c} / L_{2}},
\end{aligned}
$$

where $n_{0}$ is the axial compression ratio; $K_{\mathrm{e}}$ is the elastic lateral stiffness of the composite frame under horizontal load; $E I_{\mathrm{c}}$ and $E I_{\mathrm{b}}$ represent the sectional 


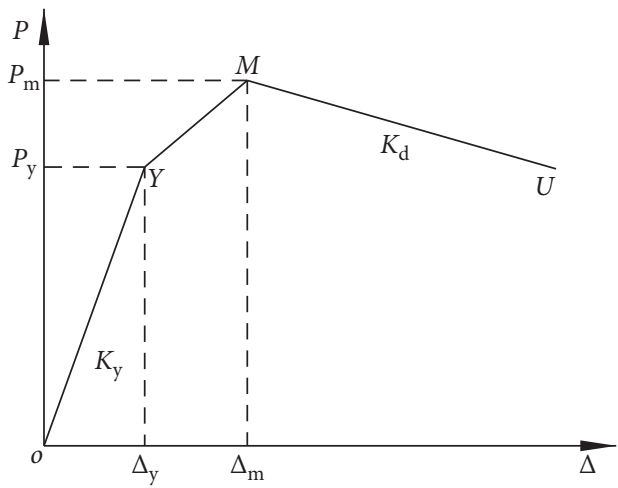

Figure 8: Skeleton curve model.

stiffness of the column and beam, respectively; $L$ is the beam length; and $H$ is the total height of the column.

(2) The expression of the regressed horizontal yield load $P_{\mathrm{y}}$ is taken as

$$
P_{y}=\left(1.35-1.17 n_{0}-0.0181 \beta+1.66 n_{0}^{2}+0.044 n_{0} \beta\right) P_{e} \text {, }
$$

where

$$
P_{e}=\frac{M_{b u 1}+M_{b u 2}+M_{c u 1}+M_{c u 2}}{L_{2}-0.5 H_{b}},
$$

where $M_{\mathrm{bu} 1}$ and $M_{\mathrm{bu} 2}$ represent, respectively, the flexural capacity at the two ends of the beam in the direction of bending deformation and $M_{\mathrm{cu} 1}$ and $M_{\mathrm{cu} 2}$ represent, respectively, the flexural capacity at the bottom of the two columns.

(3) By the analysis, the expression of peak load $P_{m}$ is given as

$$
P_{m}=\left(1.39-1.02 n_{0}-0.0071 \beta+1.62 n_{0}^{2}+0.033 n_{0} \beta\right) P_{e} \text {. }
$$

(4) Through regression analysis, the expression of the displacement $\Delta_{\mathrm{m}}$ corresponding to the peak load is as follows:

$$
\Delta_{m}=\left(-2.692+4.314 n_{0}+0.997 \beta-4.788 n_{0}^{2}-0.171 n_{0} \beta+0.05 \beta^{2}\right) \Delta_{y} .
$$

(5) The expression of the stiffness of the descending section $K_{\mathrm{d}}$ is given below by regression.

$$
K_{d}=\left(0.516 n_{0}^{2}-0.169 n_{0}+0.0242\right) K_{e} .
$$

\section{Hysteresis Rules}

The horizontal load-displacement $(P-\Delta)$ hysteretic model of the frames is provided in Figure 9. The numbers from small to large in this figure indicate the walking route of the hysteretic models during forward and reverse loading and unloading $[17,18]$. The hysteresis rule is stated as follows:

(1) Loading and unloading rules for elastic segment: before the horizontal load reaches the yield load $P_{y}$, loading and unloading are carried out along the skeleton curves; the unloading stiffness is taken as the initial stiffness, regardless of the stiffness degradation and residual deformation.

(2) Loading and unloading rules for elastoplastic stage: the loading stiffness is the incremental stiffness after yielding when the restoring force exceeds the positive or negative yield load $P_{y}$ and does not reach the ultimate bearing capacity $P_{u}$ in the positive or negative directions. According to a large number of calculated results and statistical regression, the unloading stiffness $K_{\text {un }}$ is reduced from the initial stiffness, which can be obtained as follows:

$$
K_{u n}=0.925\left(\frac{\Delta_{u n}}{\Delta_{y}}\right)^{-0.162} K_{y} .
$$

(3) Unloading rules for descending segment: when the restoring force exceeds the limit horizontal load $P_{u}$ in the positive or negative direction, the loading stiffness is taken as the stiffness of the descending segment of the skeleton curves, and the unloading stiffness of the descending segment is still computed in accordance with equation (9).

(4) Reverse reloading rules: after unloading in the forward direction and subsequent loading in the reverse direction, when the maximum displacement experienced in the reverse direction does not exceed the yield displacement $\Delta_{y}$, the loading curve will directly point to the reverse yield point from $P=0.2 P_{\text {un }}$. When the maximum displacement experienced in the reverse direction exceeds the yield displacement 


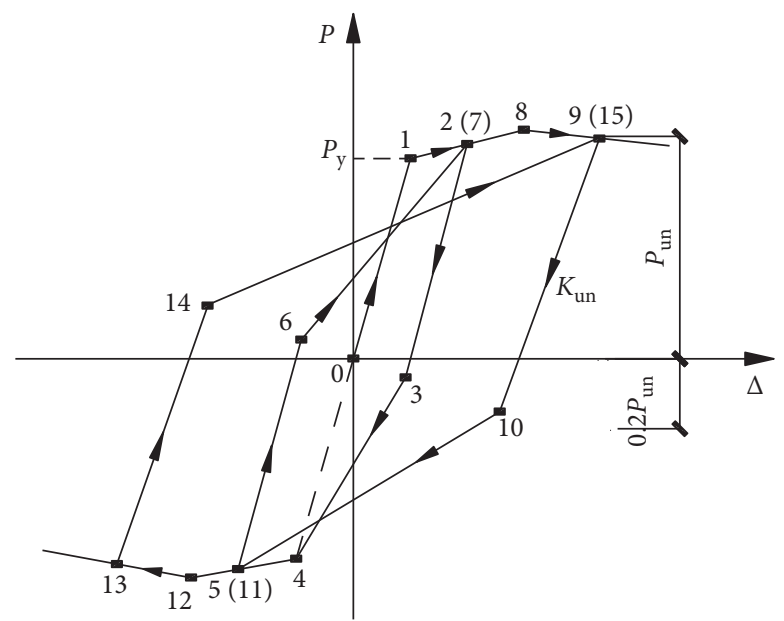

Figure 9: $(P)-\Delta$ hysteretic model.

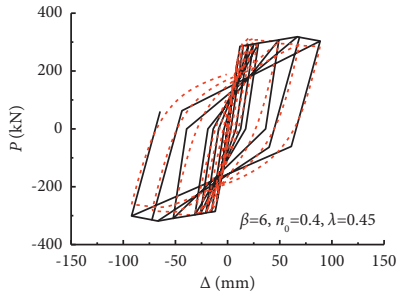

- Hysteresis model - - Numerical calculation

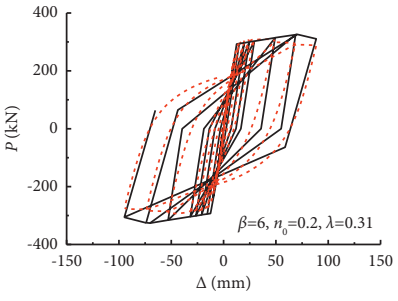

- Hysteresis model

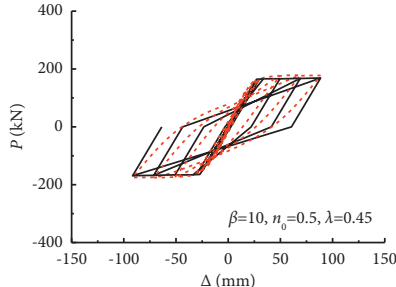

- Hysteresis model

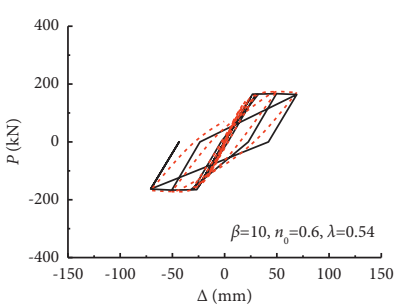

- Hysteresis model

Figure 10: Comparison between numerical calculation and hysteretic models.

$\Delta_{y}$, loading curve points directly from $P=0.2 P_{\text {un }}$ to the maximum displacement point experienced in the reverse direction; when unloading in the reverse direction and reloading in the forward direction, the loading curve will point from $P=0.2 P_{\text {un }}$ to the maximum displacement point experienced in the forward direction.

6.1. Hysteresis Model Validation. The comparison between the hysteretic curves obtained by numerical calculation and the $P-\Delta$ hysteretic models established in this paper is presented in Figure 10. The results indicate that the hysteretic curves of numerical calculation are close to the hysteretic model. It can be found that the hysteretic models established in this paper are reliable and can be used to predict the hysteretic performance of prestressed and non-prestressed steel reinforced concrete frames under horizontal loads.

\section{Conclusions}

The numerical simulation of the whole hysteretic process of the prestressed steel reinforced concrete frame under horizontal low cyclic loading is conducted, and the following conclusions are obtained:

(1) The single-storey and single-span prestressed and non-prestressed steel reinforced concrete frame numerical models established can appropriately reflect the test results and have high reliability.

(2) The calculation results of the numerical model showed that the prestressed and non-prestressed steel reinforced concrete frames had full hysteretic loop area and stable shuttle shape without obvious pinching, which showed good energy dissipation capacity.

(3) With the increase of column slenderness ratio, the frame stiffness and peak load decreased while the ductility increased; with the increase of axial compression ratio, the frame displacement ductility decreased, showing that its deformation ability is reduced.

(4) According to the parameter analysis, the hysteresis model of single-storey and single-span prestressed and non-prestressed steel reinforced concrete frames was established, which can better predict the hysteretic performance of such composite frame under horizontal load. 


\section{Data Availability}

The data used to support the findings of this study are available from the corresponding author upon request.

\section{Conflicts of Interest}

The authors declare that they have no conflicts of interest.

\section{Acknowledgments}

The authors appreciate the support of the National Natural Science Foundation of China (51878589), China Postdoctoral Science Foundation (2019M651762), Six Talent Peaks Project of Jiangsu Province (2017-JZ-038), Science and Technology Planning Project of Yangzhou City (YZ2018068), and Project of Innovation and Entrepreneurship Plan of Jiangsu Province (2019). The authors also appreciate the contribution of Guanpu Xu, Zaixian Chen, Xinyu Li, Jinyu Shi, and Ahmed Ahmad Omar.

\section{References}

[1] X. Xiong, G. Yao, and X. Su, "Experimental and numerical studies on seismic behavior of bonded and unbonded prestressed steel reinforced concrete frame beam," Engineering Structures, vol. 167, pp. 567-581, 2018.

[2] X. Xiong and G. Yao, "Studies on the static behaviors of unbonded prestressed steel reinforced low-strength concrete rectangular frame beams," Engineering Structures, vol. 171, pp. 982-991, 2018.

[3] C. G. Fu, Y. Y. Li, X. B. Sun, and J. Xu, "Experimental study on seismic performance of pre-stressed and non-prestressed steel reinforced concrete frames," Journal of Building Structures, vol. 31, no. 8, pp. 15-21, 2010, (in Chinese).

[4] K. Wang, Sh. F. Yuan, D. F. Cao, and W. Zh. Zheng, "Experimental and numerical investigation on frame structure composed of steel reinforced concrete beam and angle-steel concrete column under dynamic loading," International Journal of Civil Engineering, vol. 13, no. 2, pp. 137-147, 2015.

[5] W. Zh. Zheng and X. J. Sun, "Methods and practice on adding storeys around an existing building," Concrete Engineering International, vol. 12, no. 3, pp. 62-63, 2008.

[6] Z. Y. Liu, W. Chen, and P. F. Li, "The technique of seismic isolation in story-adding buildings using light-weight steel structure and its application," Applied Mechanics and Materials, vol. 174, pp. 2119-2121, 2012.

[7] W. Xue, L. Li, B. Cheng, and J. Li, "The reversed cyclic load tests of normal and pre-stressed concrete beams," Engineering Structures, vol. 30, no. 4, pp. 1014-1023, 2008.

[8] W. Zheng and J. Ji, "Dynamic performance of angle-steel concrete columns under low cyclic loading-II: parametric study," Earthquake Engineering and Engineering Vibration, vol. 7, no. 2, pp. 137-146, 2008.

[9] W.-D. Wang, L.-H. Han, and X.-L. Zhao, "Analytical behavior of frames with steel beams to concrete-filled steel tubular column," Journal of Constructional Steel Research, vol. 65, no. 3, pp. 497-508, 2009.

[10] L. 1. Hu, H. Zheng, and F. Xiao, "Restoring force model of steel frames infilled with the reinforced concrete deep beam," China Civil Engineering Journal, vol. 43, no. 9, pp. 49-54, 2010.

[11] K. Wang, X.-F. Lu, S.-F. Yuan, D.-F. Cao, and Z.-X. Chen, "Analysis on hysteretic behavior of composite frames with concrete-encased CFST columns," Journal of Constructional Steel Research, vol. 135, pp. 176-186, 2017.

[12] S. Mazzoni, F. McKenna, and M. H. Scott, Open System for Earthquake Engineering Simulation User Command-Language Manual, pp. 14-105, University of California, Berkeley, CA, USA, 2006.

[13] W. Zh. Zheng and Y. Wang, Uniform Design Method and Examples for Pre-stressed concrete Building Structures, Harbin: Hei long jiang Science and Technology Press, Harbin, China, 1998, in Chinese.

[14] R. Park, M. J. N. Priestley, and W. D. Gill, "Ductility of squareconfined concrete columns," Journal of the Structural Division, vol. 108, no. 4, pp. 929-950, 1982.

[15] B. D. Scott, R. Park, and M. J. N. Priestley, "Stress-strain behavior of concrete confined by overlapping hoops at low and high strain rates," Aci Journal, vol. 79, no. 1, pp. 13-27, 1982.

[16] I. D. Karsan and J. O. Jirsa, "Behavior of concrete under compressive loadings," Journal of the Structural Division, vol. 95, no. 12, pp. 2543-2564, 1969.

[17] Y. Fukada, "A Study on the Restoring Force Characteristics of Reinforced concrete Buildings," in Proceedings of the Kanto District Symposium of AIJ, Tokyo, Japan, 1969.

[18] O. Kustu and J. G. Bouwkamp, "Behavior of Reinforced concrete Deep Beam-Columns Subassemblages under Cyclic Loads," UCB/EERC Report 73 82, University of California, Berkeley, CA, USA, 1973. 